\title{
Role of alternative splicing of periostin in human bladder carcinogenesis
}

\author{
CHUL JANG KIM ${ }^{1}$, TAKAHIRO ISONO ${ }^{2}$, YUKIHIRO TAMBE ${ }^{3}$, TOKUHIRO CHANO ${ }^{4}$, \\ HIDETOSHI OKABE ${ }^{4}$, YUSAKU OKADA ${ }^{5}$ and HIROKAZU INOUE ${ }^{3}$ \\ ${ }^{1}$ Department of Urology, Kohka Public Hospital, 3-39 Rokushin, Kohka, Shiga 528-0014; \\ ${ }^{2}$ Central Research Laboratory, Departments of ${ }^{3}$ Microbiology, ${ }^{4}$ Clinical Laboratory Medicine and ${ }^{5}$ Urology, \\ Shiga University of Medical Science, Setatsukinowa-cho, Otsu, Shiga 520-2192, Japan
}

Received July 30, 2007; Accepted September 20, 2007

\begin{abstract}
We have previously reported that the expression of periostin mRNA is significantly repressed in human bladder cancer tissues, and that periostin plays a role as a suppressive factor for invasion and metastasis in the progression of human bladder cancers. In this study, to clarify the role of alternative splicing of periostin in human bladder carcinogenesis, we examined the expression of wild-type (WT) and spliced variants of periostin mRNA in normal bladder and bladder cancer tissues. Although both WT and spliced periostin mRNA were expressed in all normal bladder tissues examined, no WT periostin mRNA was detected in the examined transitional cell carcinomas (TCCs) of the bladder $(0 / 23)$ or in bladder cancer cell lines $(0 / 6)$. Spliced variants of periostin were detected in $48 \%(11 / 23)$ of TCC tissues and $33 \%(2 / 6)$ of bladder cancer cell lines. Two types of spliced periostin (Variants I and II) were successfully isolated from bladder cancer tissues, but Variant I, which is predominantly expressed in bladder cancer tissues, did not show suppressor activity on in vitro invasiveness and in vivo metastasis of cancer cells. Immunohistochemical analysis indicated that strong belt-like expression of periostin protein was observed in the stroma just beneath the normal bladder epithelium, while it was mostly attenuated in bladder cancer tissues. These results indicate that the loss of WT periostin by down-regulation and/or alternative splicing, which produces Variant I, is closely correlated with the development of bladder cancer.
\end{abstract}

Correspondence to: Dr Hirokazu Inoue, Deparment of Microbiology, Shiga University of Medical Science, Setatsukinowa-cho, Otsu, Shiga 520-2192, Japan

E-mail: hirokazu@belle.shiga-med.ac.jp

Key words: periostin, alternative splicing, bladder cancer, metastasis, invasion

\section{Introduction}

Periostin was initially shown to be highly expressed in early osteoblastic cells in vitro and in periosteum and periodontal ligament tissues in vivo, and it is known to play a role in bone and tooth formation and maintenance of structure in these tissues (1). Additionally, periostin has been shown to be involved in the cell adhesion and spreading of osteoblastic cells (1). Recently, it has been reported that periostin expression is correlated with heart failure (2), and that mechanical pressure stress induces the expression of periostin in fibroblasts in the heart (3) and in the periodontal ligaments (4). Periostin null mice exhibit dwarfism, incisor enamel defects, and an early-onset periodontal disease-like phenotype, suggesting that periostin is required for maintenance of the integrity of the periodontal ligaments in response to mechanical stress (5). Periostin has a typical signal peptide sequence at its $\mathrm{N}$-terminus and four repeated domains (RDs) (Fig. 1). Each of latter contains two highly conserved sequences which have been found in the fasciclin I family of proteins $(1,6)$. Periostin is especially highly homologous to Big-h3, a member of the fasciclin I family which has been isolated as a transforming growth factor $\beta$ (TGF- $\beta$ )responsive gene (7). Big-h3 promotes cell adhesion and fibroblast spreading via integrin $\alpha 1 \beta 2(8,9)$ and suppresses the ability of Chinese hamster ovary $(\mathrm{CHO})$ cells to develop into tumors in nude mice (10). The expression of periostin is also increased by TGF- $\beta$ (1), and periostin mRNA expression is down-regulated by the introduction of Wnt-3 and by the inhibition of glycogen synthase kinase 33 (GSK-3ß) (11), suggesting that loss of periostin expression could promote oncogenesis. However, in most human tumors, including colon cancer (12), breast cancer (13), lung cancer (14), head and neck cancer (15), oral cancer (16) and pancreatic cancer (17), periostin expression has been shown to be up-regulated; however, this is not true of bladder cancer (18).

In previous studies, we have isolated the periostin gene as a transformation-suppressive gene from a subtracted cDNA library highly enriched in rat embryo fibroblast (REF)specific genes, and found that the expression of periostin mRNA was markedly reduced in a variety of human cancer cell lines $(19,20)$. Previously, we reported that the down- 

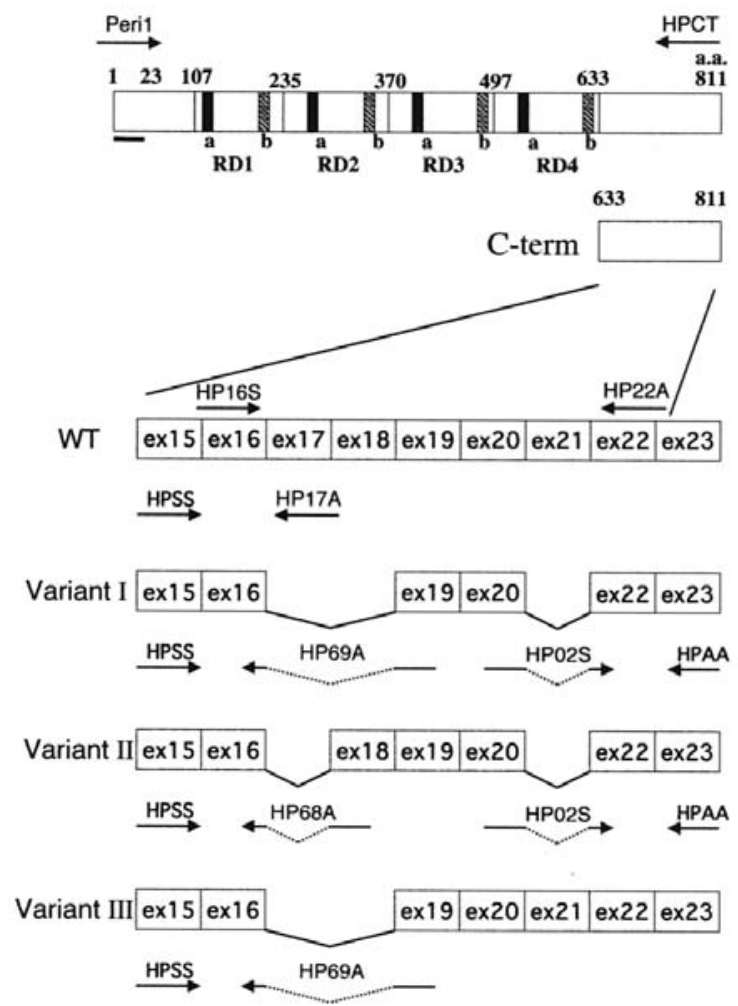

Figure 1. Structure of wild-type (WT) and spliced periostin (Variants I, II and III). The bar at the N-terminus represents the position of the typical signal peptide sequence. Repeated domains (RDs) each contain 2 highly conserved sequences that are indicated by black boxes (a) and hatched boxes (b). Exons 17, 18 and 21 are spliced out in Variant I, exons 17 and 21 are spliced out in Variant II and exons 17 and 18 are spliced out in Variant III. The arrows indicate the positions of primers.

regulation of periostin mRNA expression is associated with higher grade in human bladder cancers, and that ectopic expression of periostin by retrovirus vector could suppress in vitro invasiveness and in vivo lung metastasis of cancer cells without affecting cell proliferation and tumor growth in nude mice (18). Our mutational analysis revealed that the C-terminal region of periostin is necessary and sufficient for the suppression of both in vitro cell invasiveness and in vivo lung metastasis (18). It has been reported that alternative splicing events occur within this C-terminal region of periostin in mice (1). In human periostin, three variants, which are produced by alternative splicing events within the C-terminal region, are registered in the Gene Bank (Fig. 1). Although recent reports suggested that in mice, spliced variants of periostin play crucial roles in adult cardiac myocyte growth following mechanical overload (21) and in osteoblast differentiation (22), the relationship between alternative splicing of periostin and human carcinogenesis has not yet been elucidated.

In the present study, to clarify the role of alternative splicing of periostin in human bladder carcinogenesis, we investigated whether alternative splicing events actually occur in bladder cancer tissues and identified the role of spliced variants of periostin in the invasiveness and metastasis of cancer cells. Furthermore, we also examined the localization of periostin protein in normal bladder and bladder cancer tissues using an immunohistochemical method.

\section{Materials and methods}

Patients and tissue specimens. Bladder tumor tissue specimens were obtained from 23 patients undergoing radical cystectomy or transurethral resection of the bladder tumor (TUR-Bt) for bladder tumor at Shiga University Hospital (Table I). Normal bladder tissue specimens were obtained from 5 patients undergoing radical cystectomy for bladder tumor; the specimens were carefully dissected away from the closed attached submucosal tissues. All surgical specimens were immediately frozen and stored in liquid nitrogen. Informed consent was obtained from all patients for these studies. Pathological staging of the primary bladder tumor was performed according to the American Joint Committee on Cancer 1997 TNM classification. Tumor grade was defined according to the WHO/International Society of Urological Pathological classification.

Cell lines. The human cancer cell lines used in the present study were bladder cancer cell lines (SBT31A, HT1197, T24, KK47, UM-UC-3 and SBT991), colon cancer cell lines (COLO201, COLO320, DLD1, LOVO and SW837), prostate cancer cell lines (DU145, LNCaP and PC3), a small cell lung cancer cell line (H69), a cervical cancer cell line (HeLa) and a malignant melanoma cell line (MeWo). Bladder and prostate cancer cell lines were cultured in RPMI-1640 medium supplemented with $10 \%$ fetal calf serum (FCS), penicillin $(100 \mathrm{U} / \mathrm{ml})$ and streptomycin $(100 \mu \mathrm{g} / \mathrm{ml})$ at $37^{\circ} \mathrm{C}$ in a humidified $5 \% \mathrm{CO}_{2}$ atmosphere. The other human cancer cell lines, the mouse malignant melanoma cell line B16F10, and human embryo fibroblasts (HEF) were cultured in Dulbecco's modified Eagle's medium (DMEM) supplemented with $10 \%$ FCS, penicillin $(100 \mathrm{U} / \mathrm{ml})$ and streptomycin $(100 \mu \mathrm{g} / \mathrm{ml})$ at $37^{\circ} \mathrm{C}$ in a humidified $5 \% \mathrm{CO}_{2}$ atmosphere.

Reverse transcriptase-polymerase chain reaction ( $R T-P C R)$ analysis. Total RNA was isolated from cultured cells and human tissues by the acid guanidine-thiocyanate/phenol/ chloroform method and subjected to RT-PCR using SuperScript II (Invitrogen, Carlsbad, CA, USA) following the manufacturer's protocol. Three spliced variants of human periostin in addition to the wild-type (WT) are registered in the Gene Bank. These variants lack exons 17, 18 and 21 (Variant I, accession number AY918092), exons 17 and 21 (Variant II, accession number AY14046) and exons 17 and 18 (Variant III, accession number D13665). We constructed primer sets which were able to detect the four transcripts, according to the human periostin gene (accession number NM_006475) (Fig. 1). The primers HP16S (5'-GTGGTAGC ACCTTCAAAGAAATCC-3', nucleotide 1981-2004) and HP22A (5'-GCAACTTCCTCACGGGTGTGTC-3', nucleotide 2463-2442) amplify C-terminal region of human periostin and detect all of the four transcripts. To detect the four transcripts distinctly, we constructed spliced gene-specific primers, which covered spliced junction sites and detected deletions of exon, as described previously (23). The primers HPSS (5'-TTCATTGGAAAAGGATTTGAACCTG-3', nucleotide 1725-1749) and HS17A (5'-GGCTGAAGAC TGCCTTCAATCAC-3', nucleotide 2083-2061) distinguish the WT transcript from three spliced variants by detecting the 
Table I. Clinicopathological features of bladder cancer patients.

\begin{tabular}{|c|c|c|c|c|c|}
\hline \multirow{2}{*}{$\begin{array}{l}\text { Case } \\
\text { number }\end{array}$} & \multirow{2}{*}{$\begin{array}{c}\text { Age } \\
\text { (years) }\end{array}$} & \multirow[t]{2}{*}{ Gender } & \multirow{2}{*}{$\begin{array}{l}\text { Surgical } \\
\text { treatment }\end{array}$} & \multicolumn{2}{|c|}{ Histopathological diagnosis } \\
\hline & & & & TNM & Grade \\
\hline 1 & 67 & M & Radical Cystectomy & pT2bN0M0 & G3 \\
\hline 2 & 54 & M & Radical Cystectomy & pT2bN0M0 & G3 \\
\hline 3 & 54 & M & Radical Cystectomy & pT2aN0M0 & G3 \\
\hline 4 & 64 & M & TUR-Bt & pTaNOMO & $\mathrm{G} 2$ \\
\hline 5 & 60 & M & TUR-Bt & pTaNOM0 & $\mathrm{G} 2$ \\
\hline 6 & 57 & $\mathrm{M}$ & TUR-Bt & pT1N0M0 & G2 \\
\hline 7 & 65 & M & TUR-Bt & pTaNOM0 & G1 \\
\hline 8 & 60 & $\mathrm{~F}$ & TUR-Bt & pTaNOM0 & G1 \\
\hline 9 & 69 & M & Radical Cystectomy & pT3bN0M0 & G3 \\
\hline 10 & 68 & $\mathrm{M}$ & Radical Cystectomy & pT3bN0M0 & G3 \\
\hline 11 & 56 & M & Radical Cystectomy & pT1N0M0 & G3 \\
\hline 12 & 64 & M & Radical Cystectomy & pT2bN0M0 & G3 \\
\hline 13 & 65 & M & Radical Cystectomy & pT2bN0M0 & G3 \\
\hline 14 & 66 & $\mathrm{M}$ & Radical Cystectomy & pT1N0M0 & $\mathrm{G} 2$ \\
\hline 15 & 74 & $\mathrm{M}$ & TUR-Bt & pTaN0M0 & G3 \\
\hline 16 & 79 & M & TUR-Bt & pTaNOM0 & G2 \\
\hline 17 & 60 & M & TUR-Bt & pTaNOM0 & $\mathrm{G} 2$ \\
\hline 18 & 61 & M & TUR-Bt & pTaNOM0 & $\mathrm{G} 2$ \\
\hline 19 & 73 & $\mathrm{M}$ & TUR-Bt & pTaN0M0 & G1 \\
\hline 20 & 65 & M & TUR-Bt & pTaNOM0 & G1 \\
\hline 21 & 69 & M & TUR-Bt & pTaNOM0 & G1 \\
\hline 22 & 49 & M & TUR-Bt & pTaNOM0 & G1 \\
\hline 23 & 70 & M & TUR-Bt & pTaNOM0 & G1 \\
\hline
\end{tabular}

exon 17. The primers HPSS and HP68A (5'-TGACTTT TGTTAGTGTGGGTC/TAT-3', nucleotide 2121-2101/20192017) detect Variant II, which lacks exon 17. The primers HPSS and HP69A (5'-TGGTGTATTTTTTAATAATTG GCT/TAT-3', nucleotide 2213-2191/2019-2017) detect Variants I and III, which lack exons 17 and 18. The primers HP02S (5'-CTCTGAAGAAATTGTTACAAGAAG/AC-3', nucleotide 2335-2358/2443-2444) and HPAA (5'-AGG CTAACTCCACAATTTCCCTC-3', nucleotide 2714-2692) detect Variants I and II, which lack exon 21. Glyceraldehyde3-phosphate dehydrogenase (GAPDH) primers were GAPDH-5F (5'-ACCACAGTCCATGCCATCAC-3') and GAPDH-3R (5'-TCCACCACCCTGTTGCTGTA-3'). Except in the case of PCR of GAPDH, PCR was performed with 30 cycles consisting of denaturation at $94^{\circ} \mathrm{C}$ for $30 \mathrm{sec}$, annealing at $55^{\circ} \mathrm{C}$ for $30 \mathrm{sec}$, and extension at $72^{\circ} \mathrm{C}$ for $30 \mathrm{sec}$, followed by a final extension for $7 \mathrm{~min}$. PCR of GAPDH was performed with annealing at $60^{\circ} \mathrm{C}$. The PCR products were separated by electrophoresis in a $2 \%$ agarose gel containing ethidium bromide and then photographed.

Immunocytochemistry. For microscopic analysis, cells were grown to $50-70 \%$ confluence in Lab-Tek II CC2 Chamber Slides (8-well; Nalge Nunc, Rochester, NY, USA). The medium was removed and the cells were rinsed with phosphate buffered saline (PBS), then fixed with $4 \%$ paraformaldehyde for $10 \mathrm{~min}$ at room temperature. After rinsing, the cells were permeabilized with $0.1 \%$ Triton X-100 for 5 min at room temperature. After a 30-min block in PBS containing $0.5 \%$ bovine serum albumin (BSA), the cells were incubated with anti-Flag antibody (M2; Sigma, St. Louis, MO, USA) for $1 \mathrm{~h}$ at $37^{\circ} \mathrm{C}$. After rinsing, the cells were incubated with Alexa 488 anti-mouse IgG antibody (Molecular Probes, Eugene, OR, USA) for $30 \mathrm{~min}$ at $37^{\circ} \mathrm{C}$. Fluorescence was visualized using an Olympus IX70 inverted fluorescence microscope (Olympus, Tokyo, Japan) and images were taken at X40 magnification with MetaMorph software (Universal Imaging Corporation, West Chester, PA, USA).

PCR cloning of full-length and spliced periostin cDNA. We amplified a human gene for periostin WT and its variants from normal bladder and bladder cancer tissues derived from a patient, respectively, by PCR, using human periostinspecific primers: Peri1 (5'-GACTCAAGATGATTCCCTT T-3', nucleotide 4-23) and HPCT (5'-CTGAGAACGACCT TCCCTTAAT-3', nucleotide 2516-2495) (Fig. 1), which were synthesized according to the nucleotide sequence of the human periostin gene (accession number NM_006475). These amplified PCR fragments were cloned into the EcoRI/ blunt site of pCR3.1-FLAG-CT expression vector. The pCR3. 1-FLAG-CT was constructed by a synthesized FLAG tag cassette introduced into the EcoRI-PstI/blunt sites of pCR3.1 expression vector, and having a stop codon at the C-terminus of the FLAG tag sequence, which was caused 
by this joining. DNA sequencing of the PCR products was performed by the dideoxy-chain termination method (24) using an ABI PRISM 310 Genetic Analyzer (Applied Biosystems/Perkin-Elmer, Foster City, CA, USA).

Construction of recombinant retroviruses expressing periostin and its alternative spliced variants. Periostin genes were cut from the NheI/blunt-NotI sites of pCR3.1-FLAG$\mathrm{CT}$, and recloned into the EcoRI/blunt-NotI sites of pCXbsr retrovirus vector (25). These vectors were designated as $\mathrm{pCXbsr/WT}$ and pCXbsr/Var I, which lacked exons 17, 18 and 21 of periostin WT, and pCXbsr/Var II, which lacked exons 17 and 21 of periostin WT. pCXbsr, pCXbsr/WT, $\mathrm{pCXbsr/Var} \mathrm{I} \mathrm{and} \mathrm{pCXbsr/Var} \mathrm{II} \mathrm{were} \mathrm{each} \mathrm{cotransfected}$ with pCL-Ampho vector, which expresses an amphotropic envelope, into $293 \mathrm{~T}$ cells using Lipofectamine Plus reagent (Life Technologies, Bethesda, MD, USA) following the manufacturer's protocols. Two days after transfection, the culture supernatants were collected and used as viral stocks.

Virus infection. We plated $2 \times 10^{5}$ cells on a $60-\mathrm{mm}$ dish and cultured them overnight at $37^{\circ} \mathrm{C}$. Culture medium was removed after polybrene treatment $(2 \mu \mathrm{g} / \mathrm{ml})$ for $30 \mathrm{~min}$, and the cells were then incubated with amphotropic retrovirus for $1 \mathrm{~h}$ at $37^{\circ} \mathrm{C}$. One day after infection, cells were selected with blasticidin $\mathrm{S}(5 \mu \mathrm{g} / \mathrm{ml})$ for 10 days, and drugresistant colonies were pooled and used for assays.

In vitro invasion assay. The in vitro invasive potential of the cancer cells was determined using Matrigel ${ }^{\mathrm{TM}}$ Basement Membrane Matrix Invasion Chambers (chamber size, $6.4 \mathrm{~mm}$; membrane surface area, $0.3 \mathrm{~cm}^{2}$; pore size, $8 \mu \mathrm{m}$; BD Biosciences, Bedford, MA) following the manufacturer's instructions. Briefly, the culture supernatant used as a chemoattractant was prepared by culturing NIH3T3 cells in DMEM supplemented with $0.1 \%$ bovine albumin, $0.005 \% \mathrm{~L}(+)$ ascorbic acid, penicillin $(100 \mathrm{U} / \mathrm{ml})$ and streptomycin $(100 \mu \mathrm{g} / \mathrm{ml})$ at $37^{\circ} \mathrm{C}$ for $24 \mathrm{~h}$. Culture supernatant $(750 \mu \mathrm{l})$ was added to the well as a chemoattractant and $500 \mu \mathrm{l}$ of cell suspension at $2 \times 10^{4} \mathrm{~B} 16 \mathrm{~F} 10$ cells $/ \mathrm{ml}$ or SBT991 cells $/ \mathrm{ml}$ was added to each chamber. The chambers were incubated for 2 days in a humidified $5 \% \mathrm{CO}_{2}$ atmosphere. Non-invasive cells were removed from the upper surface of the membrane with a cotton swab. The invasive cells on the underside of the membrane were stained with Diff-Quik ${ }^{\mathrm{TM}}$ stain (Kokusaishiyaku, Kobe, Japan) and counted under a microscope. The Student's t-test was used for statistical analysis of the in vitro invasion assay. Only variables showing a value of $\mathrm{p}<0.05$ were considered statistically significant.

In vivo lung metastasis assay. To produce experimental lung metastasis, $2 \times 10^{5}$ cancer cells were injected into the lateral tail vein of 7-week-old BALB/c-nu/nu female nude mice. At 3 weeks after injection, the mice were sacrificed under anesthesia; the lungs were removed and visible metastatic colonies were counted using a dissecting microscope.

Immunohistochemical analyses. Formalin-fixed paraffinembedded tissues containing both normal and cancer
A
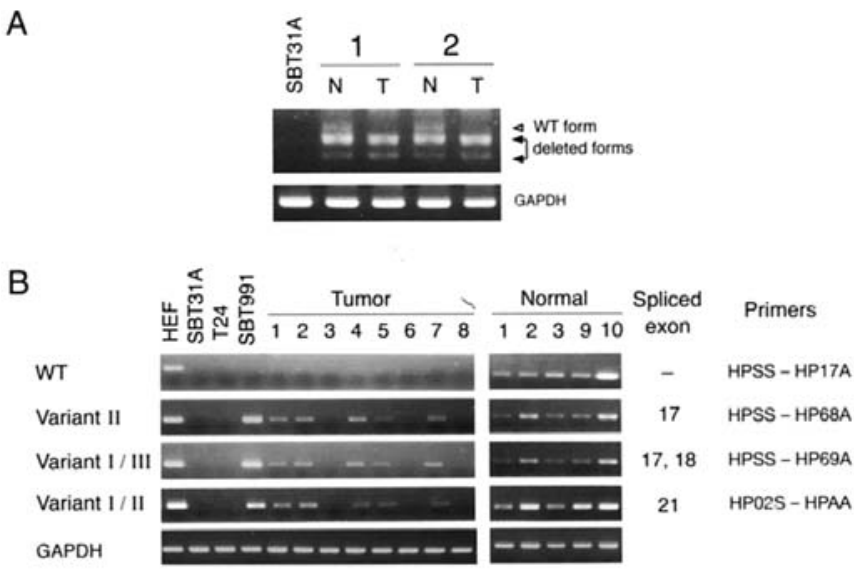

C
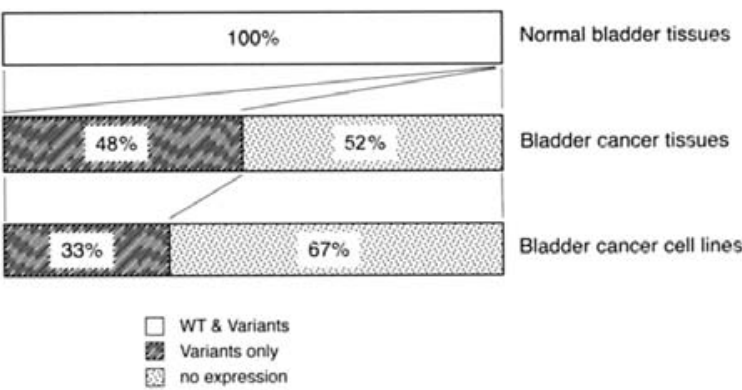

Figure 2. Expression of wild-type (WT) and spliced periostin mRNA. (A) Reverse transcriptase-polymelase chain reaction (RT-PCR) analysis of WT and deleted forms of periostin mRNA expression in normal bladder $(\mathrm{N})$ and bladder cancer $(\mathrm{T})$ tissues by using the primers which amplify the $\mathrm{C}$-terminal region, HP16S and HP22A. The expression of glyceraldehyde-3-phosphate dehydrogenase (GAPDH) was used as an internal control. (B) RT-PCR analysis of WT and spliced periostin mRNA expression in normal bladder tissues, bladder cancer tissues and cancer cell lines. The case numbers correspond to those shown in Table I. Human embryo fibroblasts (HEFs) were used as a positive control in the expression of human periostin mRNA. The expression of GAPDH was used as an internal control. (C) Expression patterns of WT and spliced variants of periostin among normal bladder tissues, bladder cancer tissues and bladder cancer cell lines. RT-PCR was performed as described in Materials and methods.

epithelia of the bladder were examined. The tissues were serially sliced, and the sections $(4 \mu \mathrm{m})$ were subjected to ordinary histological and immunohistochemical examination. Immunohistochemical detection of periostin was performed in the epithelial and stromal cells of normal bladder and bladder cancer tissues. Polyclonal antibodies against human periostin (RD-932; BioVendor Laboratory Medicine, Inc., Bmo, Czech Republic) were used. The following immunohistochemical detection was carried out using Histofine Simple Stain MAX-PO(R) according to the supplier's recommendations (Nichirei, Tokyo, Japan).

\section{Results}

Expression of WT and spliced variant transcripts of periostin in human cancer cell lines, bladder cancer tissues and normal bladder tissues. Alternative splicing events occur within the C-terminal region of periostin (1), which is a key region in the suppression of both in vitro cell invasiveness 
Table II. Expression pattern of wild-type (WT) and spliced periostin transcripts.

\begin{tabular}{l}
\hline \\
\hline Human embryo fibroblasts \\
HEFs \\
Human lung cancer cell line \\
H69 \\
Human bladder cancer cell lines \\
SBT31A \\
HT1197 \\
T24 \\
KK47 \\
UM-UC-3 \\
SBT991
\end{tabular}

Human colon cancer cell lines

COLO201
COLO320

DLD1

LOVO

SW837

Human prostate cancer cell lines
DU145
LNCaP
PC3

Human cervical cancer cell line HeLa

Human melanoma cell line MeWo

Human normal bladder tissues Case no.

1
2
3
9
10

Human bladder cancer tissues Case no.

$$
\begin{array}{r}
1 \\
2 \\
3 \\
4 \\
5 \\
6 \\
7 \\
8 \\
9 \\
10
\end{array}
$$$$
11
$$$$
12
$$$$
13
$$

Table II. Continued.

\begin{tabular}{ccc}
\hline & Wild-type & Variants \\
\hline 15 & - & - \\
16 & - & - \\
17 & - & - \\
18 & - & - \\
19 & - & + \\
20 & - & + \\
21 & - & - \\
22 & - & + \\
23 & - & - \\
\hline
\end{tabular}

and in vivo lung metastasis (18). Although three spliced variants of human periostin other than WT are registered in the Gene Bank, the correlation between these spliced variants and carcinogenesis remains unclear. To clarify the role of alternative splicing of periostin in human bladder carcinogenesis, we examined the expression of the WT and spliced variant transcripts of periostin in 17 human cancer cell lines, 23 human bladder cancer tissues (Table I) and 5 normal bladder tissues by RT-PCR. We initially amplified the C-terminal region, from exon 16 to exon 22, using HP16S and HP22A primers (Fig. 1). As shown in Fig. 2A, the bands corresponding to the size of both WT form and deletion form fragments were detected in normal bladder tissues (Case 1 and 2). The sequencing analysis of this WT form fragment verified that this fragment is actually the $\mathrm{C}$-terminal region of the WT periostin. The WT form fragment was lost in bladder cancer tissues (Fig. 2A). These deletion form fragments are considered to be derived from alternative splicing transcripts. As all spliced variants registered lack the exon 17, we used the primers HPSS and HP17A to distinguish the WT transcript from three variants transcripts (Figs. 1 and 2B). To analyze deletion form fragments precisely, we created three primer sets which could detect the existence of variant transcripts of periostin, according to the information registered in the Gene Bank. These primer sets, HPSS-HP68S, HPSS-HP69A and HP02SHPAA, were able to detect Variant II, which lacks exon 17, Variants I and III, which lack exons 17 and 18, and Variants I and II, which lack exon 21, respectively (Figs. 1 and 2B). As shown in Fig. 2 and Table II, both WT and spliced (3 types) variant transcripts of periostin were expressed in all normal bladder tissues examined. In contrast, no expression of WT periostin was detected in transitional cell carcinoma (TCC) tissues of the bladder and cancer cell lines, including 6 bladder cancer cell lines, with the exception of one human small cell lung cancer cell line, H69. Spliced variant transcripts of periostin were detected in 48\% (11/23) of TCC tissues of the bladder and in 33\% (2/6) of bladder cancer cell lines (Table II and Fig. 2C). Spliced variant transcripts of periostin were not detected in 91\% (10/11) of other cancer cell lines except for H69. The expression of the spliced variant transcripts of periostin coincided in these cancer tissues and cancer cells. These results indicate that the down-regulation 
A

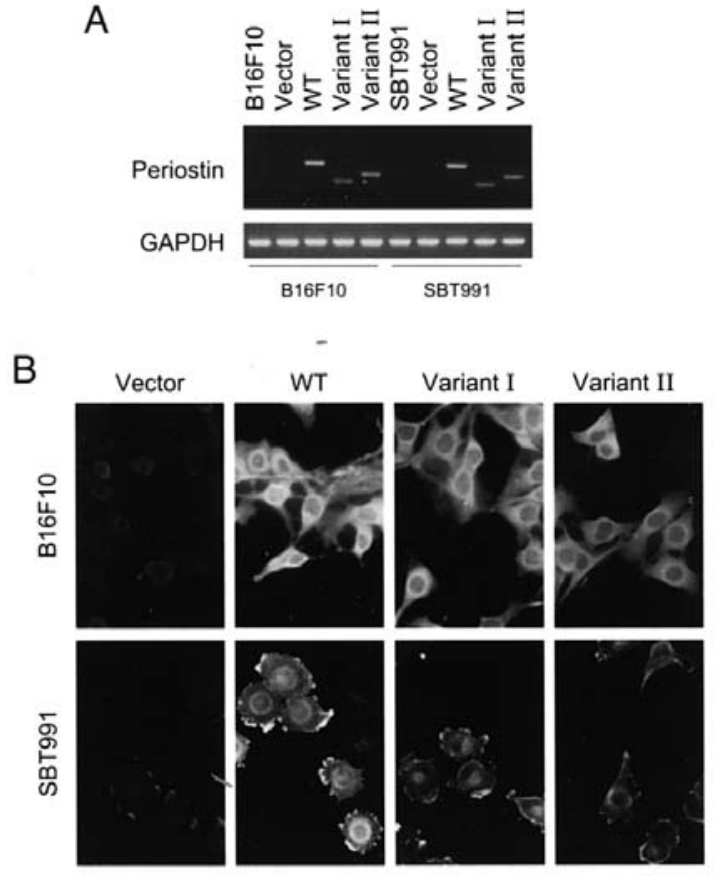

Figure 3. Ectopic expression of periostin mRNA and protein in B16F10 and SBT991 cells. (A) RT-PCR analysis of WT and spliced periostin mRNA expression in B16F10 and SBT991 cells infected with the recombinant viruses (pCXbsr/ WT, pCXbsr/Var I or $\mathrm{pCXbsr/Var} \mathrm{II)} \mathrm{or} \mathrm{the} \mathrm{control} \mathrm{virus}$ (pCXbsr). In these experiments, PCR was performed with 25 cycles consisting of denaturation at $94^{\circ} \mathrm{C}$ for $30 \mathrm{sec}$, annealing at $55^{\circ} \mathrm{C}$ for $30 \mathrm{sec}$, and extension at $72^{\circ} \mathrm{C}$ for $30 \mathrm{sec}$, followed by a final extension for $7 \mathrm{~min}$ using the primers HP16S and HP22A. (B) The immunofluorescence assay for WT and spliced periostin in SBT991 and B16F10 cells infected with the recombinant viruses (pCXbsr/WT, pCXbsr/Var I or pCXbsr/Var II) or the control virus (pCXbsr). Anti-Flag monoclonal antibody was used to detect Flag-tagged periostin protein as described in Materials and methods.

of WT periostin is closely correlated with bladder carcinogenesis. On the other hand, spliced variants of periostin nevertheless remained in about half of bladder cancer tissues, suggesting that the shift of periostin types from WT to variants by alternative splicing events may be correlated with the progression of human cancers.

Isolation of WT and spliced variant periostin cDNA from human normal bladder and bladder cancer tissues. To confirm that WT periostin transcript is expressed in normal bladder tissues and which types of spliced periostin are actually expressed in bladder cancer tissues, we attempted to isolate the full-length cDNA of the WT and spliced variants of periostin from human normal bladder tissues (Case 1) and bladder cancer tissue (Case 1), respectively. By RT-PCR cloning using the N-terminus, Peri1, and C-terminus, HPCT primers (Fig. 1), we isolated full-length WT cDNA clones of periostin, which covered from exon 1 to exon 23 , from the normal tissue specimen, indicating that WT periostin is expressed in human normal bladder tissue. By using the same primers, we isolated five cDNA clones of spliced variants of periostin from the cancer tissue specimen. Four of the five clones were Variant I and the other was Variant II. Variant I periostin was also predominantly isolated from two other bladder cancer tissue specimens. We were unable to isolate WT and Variant III periostin from the human cancer tissues in

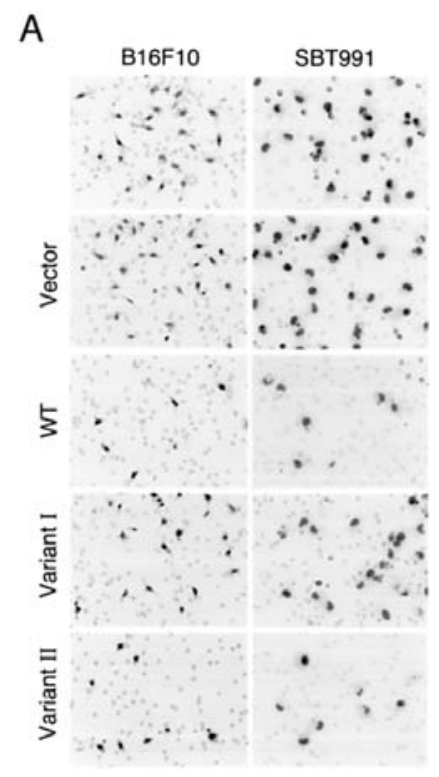

B

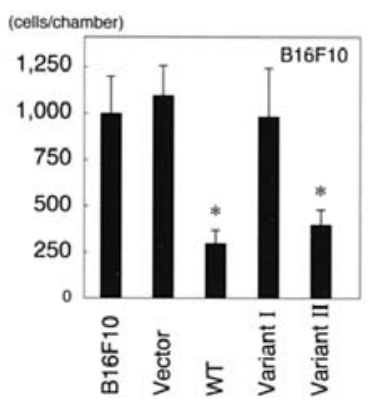

C

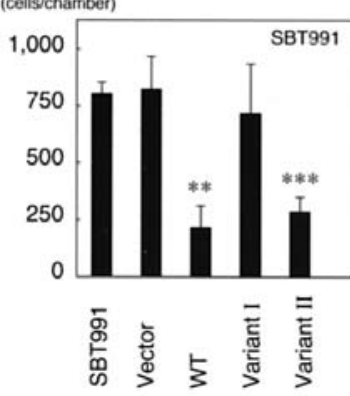

D
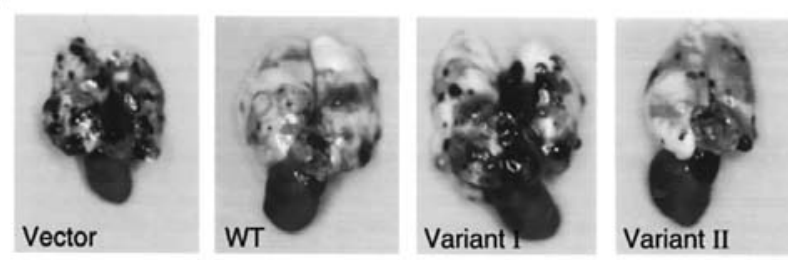

Figure 4. Effect of WT and spliced periostin on in vitro cell invasiveness and in vivo lung metastasis in SBT991 and B16F10 cells. (A) Cells invading through matrigel. The procedures are described in the Materials and methods. Photographs were taken at a magnification of X100. (B and C). The numbers of cells invading through the matrigel in B16F10 (B) and SBT991 (C) cells. Each sample was assayed in triplicate. Similar results were obtained in 3 independent experiments. Bars, \pm SE of triplicate chambers for each experiment. ${ }^{*} \mathrm{p}<0.02 ;{ }^{* *} \mathrm{p}<0.01 ;{ }^{* * *} \mathrm{p}<0.001$ as compared to the control cell line. (D) Metastatic colonies of B16F10 cells infected with the vector virus or the recombinant viruses containing WT, Variant I or Variant II periostin on the surface of the lung. The procedures are described in the Materials and methods. Each sample was assayed in triplicate. Similar results were obtained in 3 independent experiments.

Table III. Effect of wild-type (WT) and spliced periostin on lung metastasis of B16F10.

\begin{tabular}{lcc}
\hline & Number of lung colonies $^{\mathrm{a}}$ & Inhibition $(\%)$ \\
\hline Vector & $110 \pm 17.2$ & \\
WT & $24 \pm 5.1$ & 78.2 \\
Variant I & $90 \pm 4.9$ & 18.2 \\
Variant II & $31 \pm 9.6$ & 71.8 \\
\hline
\end{tabular}

${ }^{\text {a Mean }} \pm \mathrm{SD}$. We injected $2 \times 10^{5}$ cancer cells into the lateral vein of 7-week-old BALB/c-nu/nu female nude mice. Each experiment was performed in three mice.

the present study. These results suggest that Variant I is the primary form of periostin expressed in human bladder cancer tissues. 

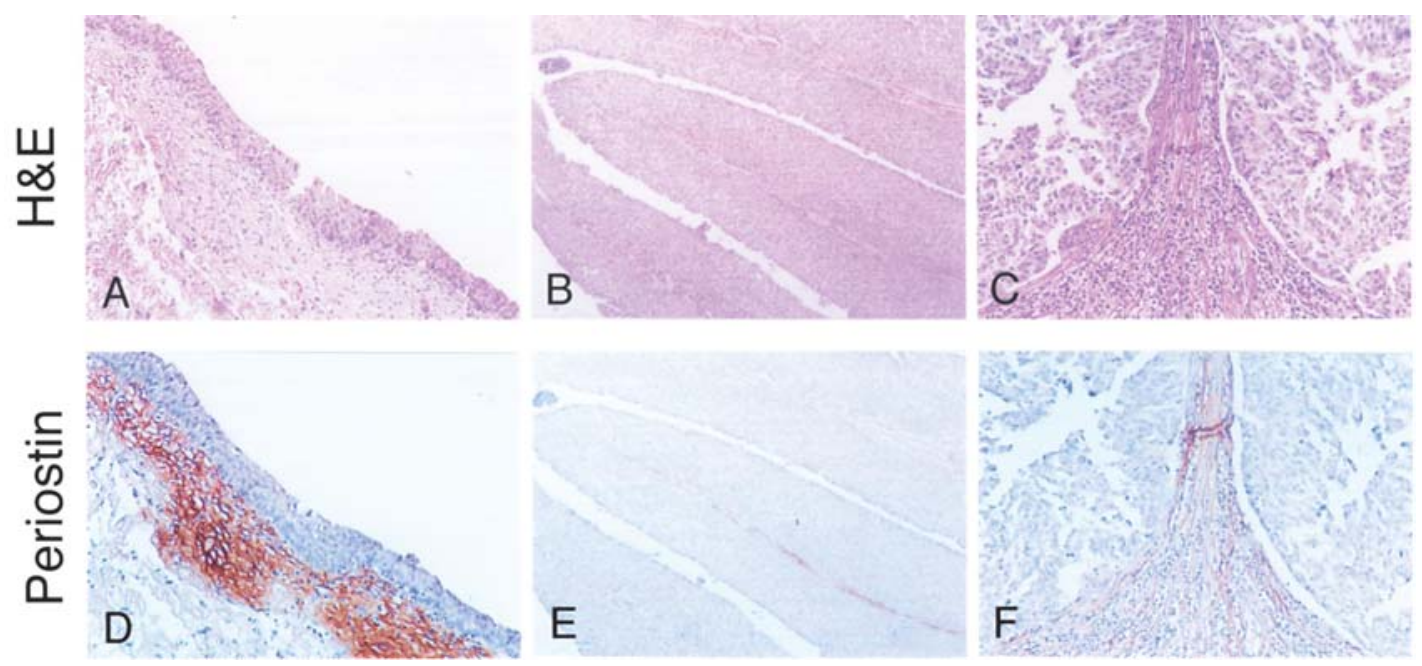

Figure 5. Localization of periostin in normal and cancerous bladder tissues. Hematoxylin-eosin (HE) (A-C) and immunohistochemical staining (D-F) of periostin in normal bladder (A and D) and bladder cancer tissues (B, C, E and F) obtained from a patient (Case 14) treated with radical cystectomy. Original magnification: (B and E) x40 and (A, C, D and F) x100.

Effect of spliced variant periostin on in vitro invasiveness and in vivo lung metastasis of cancer cells. To investigate the function of spliced periostin in the invasiveness and metastasis of cancer cells, we constructed amphotropic retroviruses containing the WT, Variant I or Variant II periostin cDNA, which were isolated from human normal and cancerous bladder tissues, tagged with Flag at its C-terminus (pCXbsr/WT, pCXbsr/Var I or pCXbsr/Var II, respectively). These recombinant viruses and a control vector virus (pCXbsr) were introduced into a human bladder cancer cell line, SBT991, and a mouse malignant melanoma cell line, B16F10 and virus-infected cells were selected, pooled and assayed. RT-PCR examination and immunofluorescence analysis with an anti-Flag antibody revealed that B16F10 and SBT991 cells infected with pCXbsr/WT, pCXbsr/Var I and pCXbsr/Var II similarly expressed WT, Variant I and Variant II periostin mRNA and protein, respectively (Fig. 3). Ectopic expression of WT or spliced periostin (Variant I or Variant II) did not affect cell proliferation (data not shown). To quantitatively evaluate the invasive potential of these cell lines, we performed an in vitro invasion assay using Matrigel ${ }^{\mathrm{TM}}$ Basement Membrane Matrix Invasion Chambers. As shown in Fig. 4, the in vitro invasiveness of cancer cell lines SBT991 and B16F10, which expressed exogenous WT or Variant II periostin, was markedly lower than that of cancer cells expressing exogenous Variant I periostin, control cells with vector or the original cancer cells, indicating that Variant I periostin lost its suppressive effect on the in vitro invasiveness of cancer cells, but that Variant II retained it.

We also examined the effect of spliced periostin on in vivo metastasis. A highly metastatic tumor cell line, B16F10, was used for this in vivo assay. We investigated the ability to induce lung metastasis after the injection of B16F10 cells infected with pCXbsr/WT, pCXbsr/Var I, pCXbsr/Var II or pCXbsr into the tail veins of nude mice. After 21 days, WT and Variant II periostin significantly suppressed metastasized colony formation on the surface of the lung as compared to the control vector. However, Variant I periostin did not have the ability to suppress in vivo metastasis of mouse melanoma cells (Fig. 4D and Table III). Taken together, these results indicate that the suppressor effect on in vitro cell invasiveness and in vivo metastasis was lost in Variant I periostin, but was retained in Variant II periostin, suggesting that alternative splicing events can affect the suppressive function of periostin with respect to invasion and metastasis.

Localization of periostin in normal and cancerous human bladder tissues. To clarify the localization of periostin protein in human bladder, we performed immunohistochemical analyses using polyclonal antibodies against human periostin in normal bladder and bladder cancer tissues. The bladder cancer cell line, T24, which expresses no periostin transcripts, did not show a positive signal, but T24 expressing exogenous human periostin reacted with this antibody, indicating that this anti-periostin antibody specifically recognizes human periostin protein (data not shown). The expression of periostin in 6 bladder cancer tissues obtained by radical cystectomy was examined. In all bladder tissues examined, strong belt-like staining of periostin was observed in the stroma just beneath the normal bladder epithelia (Fig. 5D), while the expression was detected only weakly in the stroma of bladder cancer tissues (Fig. 5E and F).

\section{Discussion}

In the present study, we investigated the expression of WT and spliced periostin mRNA in normal and cancer tissues of human bladders and human cancer cell lines by RT-PCR, finding differences in the expression patterns of WT and spliced periostin mRNA between the normal bladder and bladder cancer tissues. Both WT and spliced periostin mRNA were expressed in the normal bladder tissues, while no expression of WT periostin mRNA was detected in any of the examined bladder cancer tissues or bladder cancer 
cell lines. By RT-PCR cloning, we were able to isolate WT periostin cDNA, which has no deletions, from normal bladder tissue, indicating that WT periostin transcript was actually expressed in normal bladder. The spliced periostin mRNA was detected in $48 \%$ of bladder cancer tissues and $33 \%$ of bladder cancer cell lines, indicating that the loss of WT periostin mRNA might be a key event in bladder carcinogenesis. Spliced periostin transcripts were still expressed in one-third to one-half of bladder cancer tissues and cell lines. We isolated the cDNA of the spliced variants of periostin from bladder cancer tissues to clarify the suppressor effect of the spliced variants on invasion and metastasis. Although two types of spliced variants of periostin cDNA were isolated from bladder cancer tissues, Variant I was predominantly isolated as cDNA in bladder cancer tissues, compared to Variant II. The suppressor function for in vitro invasiveness and in vivo metastasis of cancer cells was lost in Variant I, but maintained in Variant II. These findings suggest that suppressive types of periostin (WT and Variant II) were hardly expressed in any of the bladder cancer tissues and cell lines. The alternative splicing event, which shifts the expression of periostin transcripts from WT to Variant I, is considered to be involved in the development of bladder cancers, in addition to the downregulation of WT periostin mRNA. The difference between Variants I and II is the absence or presence, respectively of exon 18. Since exon 18 of periostin might be a key exon in the suppression of in vivo lung metastasis as well as in vitro cell invasiveness, we examined the suppressive effect of the exon 18-deleted mutant periostin (delta 18) on in vitro cell invasiveness. However, the delta 18 mutant maintained suppressive function for in vitro cell invasiveness (data not shown), suggesting that the structural change of the Cterminal region, rather than the loss of the small specific motif of exon 18, may influence the function of periostin with respect to invasion and metastasis. Two other reports have also shown that alternative splicing inactivates tumor suppressor genes such as KAI1 (26) and invasion inhibitory protein 45 (IIp45) (27), resulting in the suppression of tumor metastasis and invasion. These findings suggest the critical role of alternative splicing, in addition to genetic and epigenetic alterations of oncogenes and tumor suppressor genes, in the development of cancer.

We also demonstrated that the expression of periostin protein was localized in the stroma in both normal bladder and bladder cancer tissues. The expression of periostin protein in normal stroma was higher and more tightly concentrated compared with that in bladder cancer stroma. The expression of periostin protein was difused and attenuated in the bladder cancer tissues, irrespective of the expression of variant periostin mRNA. This may be due to the conformational change of variant periostin protein by alternative splicing. In the present study, we were unable to detect the expression of periostin protein in the epithelium of either normal or cancerous bladder tissues by immunohistochemical analysis. There are two possible explanations for the expression of periostin protein and mRNA in bladder tissues. The first is that periostin mRNA and protein are expressed only in the stromal cells. The second is that periostin mRNA is also expressed in the epithelium, but that periostin protein accumulates in the stroma. Recently, Baril et al have shown that the periostin transcript is exclusively expressed in the cytoplasm of pancreatic ductal adenocarcinoma cells, but that the protein product was detected only in the juxtatumoral stroma components (17). The present RT-PCR experiments (Fig. 2 and Table II) showed that variant types of periostin mRNA were detected in bladder cancer cell lines, suggesting that bladder cancer cells can express periostin mRNA. Strong belt-like expression of periostin protein was observed in the stroma just beneath the normal bladder epithelial cells, suggesting that periostin might act in the protection of bladder mucosa from vesical pressure, because it has also been reported that mechanical pressure stress induces the expression of periostin in the heart and the periodontal ligaments $(3,4)$. Migration of cancer cells may be promoted when this structure vanishes from the bladder cancer tissues, resulting in enhancement of invasion and metastasis.

In our previous study, we have shown evidence in favor of a potential tumor suppressor function of periostin, since its ectopic expression suppressed both the invasiveness and the metastasis of human bladder cancer cells and malignant melanoma cells (18). On the other hand, several other studies have shown that the ectopic expression of periostin enhances invasion in human breast, oral and pancreatic cancer cells $(13,16,17)$, promotes metastasis in human colon cancer cells (12), and promotes invasion and metastasis in human head and neck cancer cells (15). To the best of our knowledge, no study has observed periostin expression in normal tissues such as the breast, colon and pancreas, although periostin was expressed in normal bladder tissues in the present study. In organs other than the bladder, the expression of periostin was aberrant in cancer tissues. The role of periostin in carcinogenesis may be different depending on the specific tissues and cell types. The present study indicates that alternative splicing events can alter the function of periostin for invasion and metastasis. This finding suggests the possibility that aberrant expression of the spliced type of periostin, which has lost its suppressive function, may promote invasion and metastasis in other tissues, such as in the colon, breast and pancreas. The type and/or function of the periostin might differ among different histopathological types of cancer and/or among cancer-derived organs.

\section{Acknowledgements}

We would like to thank Ms. Hiroko Kita (Department of Microbiology, Shiga University of Medical Science) for her technical assistance. This project was supported by a Grantin-Aid for Scientific Research (C) (Grant No.17591675 and No. 17590341, T. Isono and H. Inoue, respectively) from the Ministry of Education, Science, Sports, and Culture of Japan.

\section{References}

1. Horiuchi K, Amizuka N, Takeshita S, Takamatsu H, Katsuura M, Ozawa H, Toyama Y, Bonewald LF and Kudo A: Identification and characterization of a novel protein, periostin, with restricted expression to periostium and periodontal ligament and increased expression by transforming growth factor $\beta$. J Bone Miner Res 14: 1239-1249, 1999. 
2. Katsuragi N, Morishita R, Nakamura N, Ochiai T, Taniyama Y, Hasegawa Y, Kawashima K, Kaneda Y, Ogihara T and Sugimura K: Periostin as a novel factor responsible for ventricular dilation. Circulation 110: 1806-1813, 2004.

3. Wang D, Oparil S, Feng JA, Li P, Perry G, Chen LB, Dai M, John SW and Chen YF: Effects of pressure overload on extracellular matrix expression in the heart of the atrial natriuretic peptide-null mouse. Hypertension 42: 88-95, 2003.

4. Wilde J, Yokozeki M, Terai K, Kudo A and Moriyama K: The divergent expression of periostin mRNA in the periodontal ligament during experimental tooth movement. Cell Tissue Res 312: 345-351, 2003.

5. Rios H, Koushik SV, Wang H, Wang J, Zhou HM, Lindsley A, Rogers R, Chen Z, Maeda M, Kruzynska-Frejtag A, Feng JQ and Conway SJ: Periostin null mice exhibit dwarfism, incisor enamel defects, and an early-onset periodontal disease-like phenotype. Mol Cell Biol 25: 11131-11144, 2005.

6. Takeshita S, Kikuno R, Tezuka K and Amann E: Osteoblastspecific factor 2: cloning of a putative bone adhesion protein with homology with the insect protein fasciclin I. Biochem J 294: 271-278, 1993.

7. Skonier J, Neubauer M, Madisen L, Bennett K, Plowman GD and Purchio AF: cDNA cloning and sequence analysis of Big-h3, a novel gene induced in a human adenocarcinoma cell line after treatment with transforming growth factor- $\beta$. DNA Cell Biol 11: 511-522, 1992.

8. LeBaron RG, Bezverkov KI, Zimber MP, Pavelec R, Skonier J and Purchio AF: BIG-H3, a novel secretory protein inducible by transforming growth factor- $\beta$, is present in normal skin and promotes the cell adhesion and spreading of dermal fibroblasts in vitro. J Invest Dermatol 104: 844-849, 1995.

9. Ohno S, Noshiro M, Makihira S, Kawamoto T, Shen M, Yan W, Kawashima-Ohya Y, Fujimoto K, Tanne K and Kato Y: RGDCAP (Big-h3) enhances the spreading of chondrocytes and fibroblasts via integrin $\alpha 1 \beta 1$. Biochim Biophys Acta 1451: 196-205, 1999.

10. Skonier J, Bennett K, Rothwell V, Kosowski S, Plowman G, Wallace P, Edelhoff S, Disteche C, Neubauer M, Marquardt H, Rodgers J and Purchio AF: Big-h3: A transforming growth factor- $B$-responsive gene encoding a secreted protein that inhibits cell attachment in vitro and suppresses the growth of CHO cells in nude mice. DNA Cell Biol 13: 571-584, 1994.

11. Haertel-Wiesmann M, Liang Y, Fantl WJ and Williams LT: Regulation of cyclooxygenase- 2 and periostin by Wnt-3 in mouse mammary epithelial cells. J Biol Chem 275: 32046-32051, 2000.

12. Bao S, Ouyang G, Bai X, Huang Z, Ma C, Liu M, Shao R, Anderson RM, Rich JN and Wang XF: Periostin potently promotes metastatic growth of colon cancer by augmenting cell survival via the Akt/PKB pathway. Cancer Cell 5: 329-339, 2004.

13. Shao R, Bao S, Bai X, Blanchette C, Anderson RM, Dang T, Gishizky ML, Marks JR and Wang XF: Acquired expression of periostin by human breast cancers promotes tumor angiogenesis through up-regulation of vascular endothelial growth factor 2 expression. Mol Cell Biol 24: 3992-4003, 2004.

14. Sasaki H, Lo KM, Chen LB, Auclair D, Nakashima Y, Moriyama S, Fukai I, Tam C, Loda M and Fuji Y: Expression of periostin, homologous with an insect cell adhesion molecule, as a prognostic marker in non-small cell lung cancers. Jpn J Cancer Res 92: 869-873, 2001.
15. Kudo Y, Ogawa I, S. Kitajima S, Kitagawa M, Kawai H, Gaffney PM, Miyauchi M and Takata T: Periostin promotes invasion and anchorage-independent growth in the metastatic process of head and neck cancer. Cancer Res 66: 6928-6935, 2006.

16. Siriwardena BSMS, Kudo Y, Ogawa I, Kitagawa M, Kitajima S, Hatano H, Tilakaratne WM, Miyauchi M and Takata T: Periostin is frequently overexpressed and enhances invasion and angiogenesis in oral cancer. Br J Cancer 95: 1396-1403, 2006.

17. Baril P, Gangeswaran R, Mahon PC, Caulee K, Kocher HM, Harada T, Zhu M, Kalthoff H, Crnogorac-Jurcevic T and Lemoine NR: Periostin promotes invasiveness and resistance of pancreatic cancer cells to hypoxia-induced cell death: role of the $\beta 4$ integrin and the PI3k pathway. Oncogene 26: 2082-2094, 2007.

18. Kim CJ, Yoshioka N, Tambe Y, Kushima R, Okada Y and Inoue $\mathrm{H}$ : Periostin is down-regulated in high grade bladder cancer and suppress in vitro cell invasiveness and in vivo metastasis of cancer cells. Int J Cancer 117: 51-58, 2005.

19. Yoshioka N, Inoue H, Nakanishi K, Oka K, Yutsudo M, Yamashita A, Hakura A and Nojima H: Isolation of transformation suppressor genes by cDNA subtraction: lumican suppresses transformation induced by $\mathrm{v}$-src and $\mathrm{v}-\mathrm{K}$-ras. J Virol 74: 1008-1013, 2000

20. Yoshioka N, Fuji S, Shimakage M, Kodama K, Hakura A, Yutsudo M, Inoue H and Nojima H: Suppression of anchorageindependent growth of human cancer cell lines by the TRIF52/ Periostin/OSF-2 gene. Exp Cell Res 279: 91-99, 2002.

21. Litvin J, Blagg A, Mu A, Mitiwala S, Montgomery M, Berretta R, Houser S and Marqulies K: Periostin and periostin-like factor in the human heart: possible therapeutic targets. Cardiovasc Pathol 15: 24-32, 2006.

22. Litvin J, Selim AH, Montgomery MO, Lehmann K, Rico MC, Devlin H, Bednarik DP and Safadi FF: Expression and function of periostin-isoforms in bone. J Cell Biochem 92: 1044-1061, 2004.

23. Tanaka T, Isono T, Yoshiki T, Yuasa T and Okada Y: A novel form of prostate-specific antigen transcript produced by alternative splicing. Cancer Res 60: 56-59, 2000.

24. Sanger F, Nicklens S and Coulson AR: DNA sequencing with chain terminating inhibitors. Proc Natl Acad Sci USA 74: 5463-5467, 1977.

25. Akagi T, Shishido T, Murata K and Hanafusa H: v-Crk activates the phosphoinositide 3-kinase/AKT pathway in transformation. Proc Natl Acad Sci USA 97: 7290-7295, 2000.

26. Lee JH, Seo YW, Park SR, KimYJ and Kim KK: Expression of a splice variant of KAI1, a tumor metastasis suppressor gene, influences tumor invasion and progression. Cancer Res 63: 7247-7255, 2003.

27. Song SW, Fuller GN, Zheng $\mathrm{H}$ and Zhang W: Inactivation of the invasion inhibitory gene IIp45 by alternative splicing in gliomas. Cancer Res 65: 3562-3567, 2005. 